\title{
The effect of context change on conditioned defensive burying in rats
}

\author{
FERNANDO G. OBERDIECK \\ University of Colorado, Boulder, Colorado 80309 \\ and \\ CARL D. CHENEY \\ Utah State University, Logan, Utah 84322
}

\begin{abstract}
Adult male albino rats were tested for conditioned defensive burying behavior following two daily sessions ( $1 \mathrm{~h} /$ day) of preexposure to the test chamber with the shock prod absent. Subjects preexposed with the houselight and fan off (context change) exhibited less burying when tested with the houselight and fan on than did subjects preexposed and tested with the houselight and fan on (context constant). It was concluded that burying behavior is sensitive to contextual control, in that simple chamber preexposure is not sufficient for burying behavior to emerge but, rather, preexposure to the context in which testing will take place must occur.
\end{abstract}

In a series of papers, Pinel and his students have demonstrated that rats will, if suitable materials are available, bury a localized source of aversive stimulation (e.g., Pinel \& Treit, 1978, 1979; Terlecki, Pinel, \& Treit, 1979). Typically, the source of aversive stimulation is a novel, wire-wrapped, stationary prod through which the rat is administered one brief electric shock, although rats will also bury the source of an air blast (Terlecki et al., 1979), a triggered electronic flash (Davis, Whiteside, Dickson, Thomas, \& Heck, 1981), and a spout that delivers poison or Tabasco juice (Wilkie, Mac Lennan, \& Pinel, 1979).

In the basic design, rats are initially preexposed, in groups, to the experimental chamber with the bedding material present and the shock prod absent for four daily 30-min sessions. On the test day, rats are individually placed in the chamber and administered one brief electric shock through the novel shock prod. Following shock delivery, a $15-\mathrm{min}$ test period ensues, during which measures of burying behavior are gathered. The common dependent variables are the amount of time spent burying the shock prod and the height of the bedding material at the prod at the conclusion of the test.

Although Pinel and his colleagues generally preexpose rats to the test chamber for four daily 30 -min sessions, the emergence of conditioned defensive burying (CDB) is not dependent on this particular preexposure schedule. For example, Davis et al. (1981) employed a single 4-h preexposure period, and Beninger, Mac Lennan, and Pinel (1980) preexposed subjects for five 45-min sessions

Reprints should be requested from Fernando Oberdieck, Department of Psychology, University of Colorado, Boulder, Colorado 80309. prior to the CDB test. Recently, Oberdieck and Corbett (Note 1) found that two 1-h preexposure sessions are as effective as four 30-min preexposure sessions for CDB to emerge. However, Tarte and Oberdieck (Note 2) reported that CDB will not occur if rats receive no chamber preexposure prior to testing. In summary, the occurrence of CDB is dependent on some chamber preexposure, although no particular schedule of chamber preexposure is necessary.

Although the studies cited differ in the chamber preexposure schedules employed, they are similar in that, presumably, they used similar preexposure and test contexts. For instance, Oberdieck and Corbett (Note 1) preexposed and tested subjects with an overhead light and exhaust fan on. Since a growing body of literature indicates that static contextual cues are critical in the emergence and maintenance of behavior (e.g., OdlingSmee, 1975; Tomie, 1976), it is conceivable that contextual cues also play an important role in the burying preparation. If this is the case, then the presence or absence of contextual cues experienced during the chamber preexposure session is critical to the emergence of CDB in the test context. That is, if preexposure and test contexts are similar, CDB should readily emerge, a fact attested to by the studies cited. However, if preexposure and test contexts are dissimilar, then CDB should be disrupted. The following study was performed to test the hypothesis that even after chamber preexposure, a novel test context would disrupt the occurrence of $\mathrm{CDB}$.

\section{METHOD}

\section{Subjects}

Twelve adult male albino rats, with limited histories in flavor aversion studies, served. Subjects were group housed, 
six per cage, in metal hanging cages, with food and water available at all times. Subjects were 45-50 days old at the beginning of the study.

\section{Apparatus}

A rectangular enclosure $(27 \mathrm{~cm}$ wide, $44 \mathrm{~cm}$ long, $30 \mathrm{~cm}$ high), with a side panel and lid made of Plexiglas and the other walls made of wood, served as the test chamber. The floor of the chamber consisted of $5 \mathrm{~cm}$ of wood shavings purchased locally. To one side, but not attached to the chamber, was a small exhaust fan that circulated air and partially masked extraneous sounds. Approximately $2.0 \mathrm{~m}$ above the chamber was a $75-\mathrm{W} 120-\mathrm{V}$ ac white houselight that illuminated the chamber and acted as the only light source in the test room in which the chamber was located.

The shock prod was a .8-cm-diam Plexiglas rod, covered with black electrical tape, over which were wrapped two strands of uninsulated wire. When in place, the shock prod, centered on one end wall and located $2.0 \mathrm{~cm}$ above the bedding material, extended $4.5 \mathrm{~cm}$ in to the test chamber. In the test phase, aversive stimulation consisted of a brief $7.5-\mathrm{mA}$ shock delivered through the uninsulated wires wrapped around the prod.

\section{Procedure}

Subjects were randomly assigned to an experimental $(n=6)$ or a control $(n=6)$ group. Experimental, or context-change, subjects were preexposed as a group to the test chamber, with the prod absent, for $1 \mathrm{~h} / \mathrm{day}$ for 2 consecutive days. During these preexposre sessions, both the houselight and the fan were off. Control, or context-constant, subjects were similarly preexposed, except that their preexposure sessions occurred with the hou selight and fan on.

Following chamber preexposure, all subjects were individually tested, with the houselight and fan on, in the following manner. Initially, a subject was placed in the center of the test chamber facing away from the now in place shock prod. Upon the rat's first contact with the shock prod with a forepaw, the experimenter initiated a shock that was terminated by the subject's withdrawal from the prod. Following shock delivery, the subject remained in the testing apparatus for $15 \mathrm{~min}$, during which the experimenter timed the number of seconds the rat engaged in burying behavior. Burying behavior was defined as any pushing or spraying of the bedding material in the direction of the shock prod or shock-prod-containing wall. When the 15-min test ended, the subject was removed and the heights of the bedding material at the base and tip of the shock prod were measured and averaged to yield a mean-height-at-prod index. The bedding material was then smoothed to a uniform $5-\mathrm{cm}$ height, and the next subject was tested.

\section{RESULTS AND DISCUSSION}

Figure 1 shows that the context-constant group engaged in more CDB (left) and accumulated higher piles of bedding material at the shock prod (right) than the context-change group did. A Mann-Whitney U test indicated that these differences were reliable for both the time $(\mathrm{U}=2, \mathrm{p}=.004$, one-tailed test $)$ and height $(\mathrm{U}=1, \mathrm{p}=.002$, one-tailed test) measures.

This study demonstrated that, even following chamber preexposure, a novel test context will disrupt the emergence of CDB. Nonsystematic observations suggested that subjects tested in the novel context acted similarly to subjects that never had experienced chamber preexposure prior to the burying test. That is, following shock, these rats simply froze or avoided the shock

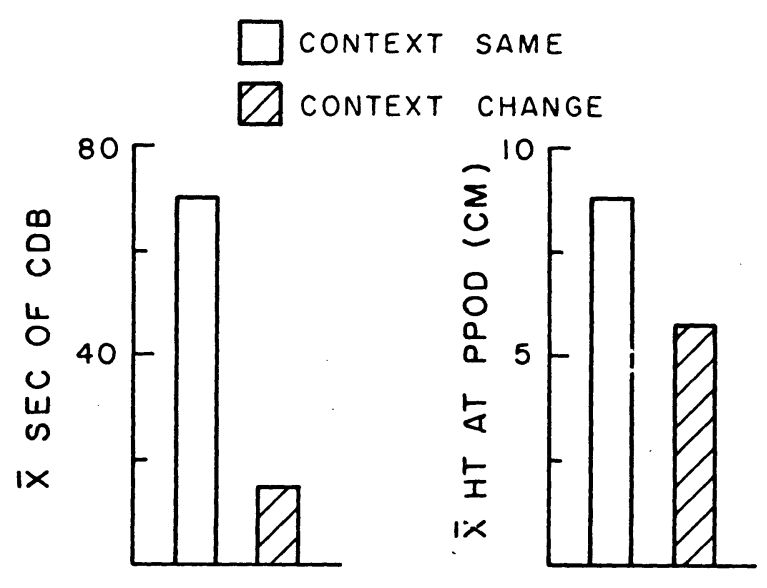

Figure 1. Mean time engaged in defensive burying (left) and mean height of bedding material at the prod (right) for contextconstant and context-change subjects.

prod rather than engage in burying behavior (see Oberdieck \& Corbett, Note 1). Tarte and Oberdieck (Note 2) maintained that some chamber preexposure prior to testing was necessary for CDB to emerge. The present findings indicate that simple preexposure is not sufficient; rather, there must be some preexposure to the context in which rats will be tested for CDB.

It must be pointed out, however, that the present study only demonstrated context-disrupting effects with one chamber preexposure schedule, namely, $1 \mathrm{~h} /$ day for 2 days. As previously noted, however, other chamber preexposure schedules are routinely employed (e.g., Beninger et al., 1980; Davis et al., 1981; Terlecki et al., 1979), and so it remains an open question as to whether or not context-disrupting effects are evidenced with all preexposure schedules. In spite of this reservation, it is apparent that contextual stimuli are as critical in CDB as in other response systems (e.g., Odling-Smee, 1975; Tomie, 1976).

\section{REFERENCE NOTES}

1. Oberdieck, F., \& Corbett, J. A. The effect of massed versus spaced preexposure on conditioned defensive burying behavior. Manuscript in preparation, 1982.

2. Tarte, R., \& Oberdieck, F. Conditioned defensive burying in rats as a function of preexposure and strain. Paper presented at the annual meeting of the Psychonomic Society, St. Louis, Missouri, November 1980.

\section{REFERENCES}

Beninger, R. J., Mac Lennan, A. J., \& Pinel, J. P. J. The use of conditioned defensive burying to test the effects of pimozide on associative learning. Pharmacology, Biochemistry, and Behavior, 1980, 12, 445-448.

Davis, S. F., Whiteside, D. A., Dickson, V. A., Thomas, R. L., \& HECK, D. G. Conditioning and retention of defensive burying as a function of Elavil and Thorazine injection. Bulletin of the Psychonomic Society, 1981, 17, 107-110. 
Odling-Smee, F. J. The role of background stimuli during Pavlovian conditioning. Quarterly Journal of Experimental Psychology, 1975, 27, 201-209.

Pinel, J. P. J., \& Treit, D. Burying as a defensive response in rats. Journal of Comparative and Physiological Psychology, 1978, 92, 708-712.

Pinel, J. P. J., \& Treit, D. Conditioned defensive burying in rats: Availability of burying materials. Animal Learning \& Behavior, 1979, 7, 392-396.

Terlecki, L. J., Pinel, J. P. J., \& Treit, D. Conditioned and unconditioned defensive burying in the rat. Learning and Motivation, 1979, 10, 337-350.

ToмIE, A. Interference with autoshaping by prior context conditioning. Journal of Experimental Psychology: Animal Behavior Processes, 1976, 2, 323-334.

Wilkie, D. M., Mac Lennan, A. J., \& Pinel, J. P. J. Rat defensive burying: Burying noxious food. Journal of the Experimental Analysis of Behavior, 1979, 31, 299-306.

(Received for publication February 27, 1982.) 